\title{
The Effects of Market Orientation on Employees: A Study of Retail Organizations in Botswana
}

\author{
Godfrey Themba ${ }^{1} \&$ Edward E. Marandu ${ }^{1}$ \\ ${ }^{1}$ Department of Marketing, University of Botswana, Gaborone, Botswana \\ Correspondence: Godfrey Themba, Department of Marketing, University of Botswana, Private bag 0022, \\ Gaborone, Botswana. Tel: 267-35-52-980. E-mail: thembag@mopipi.ub.bw
}

Received: November 3, 2012

Accepted: November 29, $2012 \quad$ Online Published: December 7, 2012

doi:10.5539/ibr.v6n1p130

URL: http://dx.doi.org/10.5539/ibr.v6n1p130

\begin{abstract}
The present study applies the MARKOR scale to investigate the posited positive effect of market orientation on employees' commitment to the organization and team spirit in a retail sector context in Botswana. The results of the present study provide empirical support for the posited link between market orientation and organizational commitment. Contrary to previous studies the present study does not lend support to the posited effect of market orientation on team spirit. Although this finding seems to be counter intuitive, it does not come as a surprise since the majority of retail businesses in Botswana are relatively small, and do not therefore rely very much on team work. From a managerial perspective the results of the present study suggest that there is much more to be gained from adopting and implementing the marketing concept other than improvement in business performance. The study also confirms the general applicability of MARKOR scale.
\end{abstract}

Keywords: market orientation, retail sector, Botswana, organizational commitment, team work

\section{Introduction}

The adoption and implementation of the marketing concept has long been regarded as the cornerstone of marketing practice (Drucker, 1954). The marketing concept is an overarching business philosophy that creates superior value for customers (Narver \& Slater, 1990). According to Jaworski and Kohli (1990) Market Orientation (MO) is a set of activities and behaviors that reflect the degree to which the marketing concept has been adopted as a business philosophy. Since the last few decades a growing body of marketing literature has acknowledged the positive effects of market orientation on organizational performance (e.g. Jaworski \& Kohli, 1993; Narver \& Slater, 1990). At the individual level, MO has also been found to be positively related to organizational commitment, esprit de corps, and job satisfaction (Jaworski \& Kohli, 1993; Ruekert 1992; Siguaw et al., 1994; Selnes et al., 1996; Caruana \& Calleya, 1998; Powpaka, 2006; Kohli \& Jaworski, 1990; Narver \& Slater,1990; Shoham et al., 2005). However, the majority of the studies in this area have largely focused on the effects of MO on organizational performance (e.g. Kohli \& Jaworski, 1990; Narver \& Slater, 1990; Diamantopoulos \& Hart, 1993; Pitt et al., 1996). Relatively few studies have investigated the effects of MO on employees (Jaworski \& Kohli, 1990; Jaworski \& Kohli, 1993; Ruekert 1992; Siguaw et al., 1994; Selnes et al., 1996; Caruana \& Calleya, 1998; Powpaka, 2006; Caruana et al., 1997). This is despite the fact that previous scholars in this area have called for more research into MO and its consequences (Kohli \& Jaworski, 1990; Cadogan \& Diamantopoulos, 1995; Narver \& Slater, 1990). Moreover, Caruana and Calleya (1998) have suggested that organizational commitment is an antecedent to organizational performance arguing that lack of organizational commitment can result in inferior service offerings, higher costs and poor performance. Similarly, Shoham et al. (2005) have provided evidence indicating that organization commitment and team spirit have a positive influence on performance.

In order to address the research gaps identified above, the present study investigates the effects of MO on employees in a specific context of the retail sector in Botswana. More specifically the study investigates the posited influence of MO on organizational commitment and esprit de corps (team spirit). A relatively small country with a stable political environment and sound macroeconomic management, Botswana's political economy makes it an interesting setting for the study of MO and its effects on employees (Selnes et al., 1996). Most of the previous studies on MO in Africa have been conducted in large economies such as Ghana (e.g. Kuada \& Buatsi 2005), Ivory Coast (e.g. Chelariu et al., 2002) and Nigeria (e.g. Winston \& Dadzie, 2002). In 
Botswana only one study has been reported to date (Marandu \& Themba, 2009). The retail sector was selected for study due to its growing importance to the economy of Botswana (Iyanda et al., 2009; A. T. Kearney Report, 2012). Retailing has also been the focus of MO studies in other countries such as the UK (Harris \& Ogbonna, 2000).

The paper is set out as follows: after the introduction follows literature review, methodology and presentation of the main findings. We then discuss the main findings and present managerial implications. Finally, limitations of the study and directions for future research are presented.

\section{Literature Review}

Since the pioneering study of Kohli and Jaworski (1990), few studies have investigated the effects of MO on employees (e.g. Ruekert, 1992; Jaworski \& Kohli, 1993; Selnes et al., 1996; Caruana et al., 1997; Castro et al., 2005; Shoham et al., 2005). In their study, which focused on US based companies, Kohli and Jaworski (1990) found that market orientation was positively related to employees' organizational commitment and esprit de corps (team spirit). Later Ruekert (1992) provided further evidence in support of the posited influence of MO on organizational commitment of employees. In yet another study Jaworski and Kohli (1993) analyzed two national samples of manufacturing companies in the US and also found evidence indicating that market orientation is strongly and positively associated with organizational commitment and esprit de corps. Jaworski and Kohli (1993, p. 64) then concluded that market orientation "nurtures a bonding between employees and the organization, as well as promotes a feeling of belonging to one big organizational family dedicated to meeting and exceeding market needs". Siguaw et al., (1994) in a study of sales force behaviors in the US found that market orientation significantly and positively influenced job satisfaction and organizational commitment.

Similar studies have also been conducted outside the US and in different organizational contexts (e.g. Caruana et al., 1997; Selnes et al., 1996; Powpaka, 2005; Mahmoud, 2011; Rod \& Ashill, 2010). In Australia, for example, Caruana et al. (1997) explored the effects of MO on organizational commitment in the public sector and their findings mirrored those from US studies. Moreover, Caruana et al. (1997) reported a strong positive association between market orientation and the affective dimension of organizational commitment, suggesting that MO makes employees become more attached to the organization and more willing to contribute towards its goals. In New Zealand Rod and Ashill (2010), investigated State Owned Enterprises (SOEs) and found that MO has a significant positive impact on job satisfaction and organizational commitment of frontline employees. Selnes et al. (1996) also investigated these issues in a comparative study of Scandinavia and USA companies and established linkages between MO and organizational commitment and team spirit. Shoham et al. (2005, p. 446) employed a substantive meta-analysis methodology and concluded that their study supported "the notion that MO has a positive impact on organizational commitment, esprit de corps, and performance".

However, not all the findings on MO and its influence of employees indicate robust linkages. For example, Castro et al. (2005), in their study of Spanish financial institutions, reported a positive but weak association between market orientation and organizational commitment. This finding suggests that in the context of financial institutions the adoption and implementation of market orientation may not lead to significant improvement in organizational commitment. According to Castro et al. (2005) lack of organizational systems and structures favorable to employees contributes to the weak relationship between $\mathrm{MO}$ and organizational commitment. In Ghana Mahmoud (2011) also found a positive but weak relationship between market orientation and organizational commitment. Their study investigated market orientation among Small and Medium Enterprises (SMEs) in Ghana. Their finding also suggests that the improvement of market orientation by SMEs based in Ghana may not lead to significantly high levels of commitment. In Thailand Powpaka (2005) investigated the effects of market orientation on female service employees and found only a marginal positive impact on organizational commitment. According to Harris and Ogbonna (2000), employees respond differently to market-oriented culture change, which implies that it is difficult to predict the impact of MO on employees. Their study sought to find out how frontline employees respond to market-oriented culture change programs amongst UK retail outlets.

From the extant literature reviewed it is evident that previous studies generally concur that MO increases commitment to the organization and that it also engenders the spirit of team work amongst employees. It is also evident from previous research findings that the strength of the association between $\mathrm{MO}$ and organizational commitment is stronger in developed countries than in developing countries. For example, studies conducted in more developed countries such as USA (e.g. Jaworski \& Kohli, 1993) and Australia (e.g. Caruana et al., 1997) have generally reported strong positive association while those conducted in less developed countries such as Spain (e.g. Castro et al., 2005), Thailand (e.g. Powpaka, 2005) and Ghana (e.g. Mahmoud, 2011) have reported 
positive but weak association between MO and organizational commitment. The extant literature also shows that the majority of the studies of MO and its effects on employees have been mostly conducted in the sales departments of the manufacturing sector (e.g. Siguaw et al., 1994; Selnes et al., 1996). Similarly, the extant literature indicates that more research studies have been conducted in developed countries than in developing nations. This is despite the fact that previous researchers have called for more research on $\mathrm{MO}$ and its consequences to be conducted in different national and organizational contexts (Kohli \& Jaworski, 1990; Shoham et al., 2005; Ellis, 2004b as cited in Ellis, 2004).

The present study addresses the shortcomings identified in the extant literature by investigating the posited influence of MO on organizational commitment and team spirit in a specific context of the retail sector in Botswana.

\section{Conceptual Model and Hypotheses}

The present study is based on a conceptual model (Figure 1) adapted from Kohli and Jaworski (1990). According to this model market orientation (MO) is defined as a construct with three dimensions: organization-wide intelligence generation (IG), intelligence dissemination (ID) and intelligence responsiveness (IR). Furthermore the market orientation domain has a direct influence on organizational commitment (OC) and team spirit (TS).

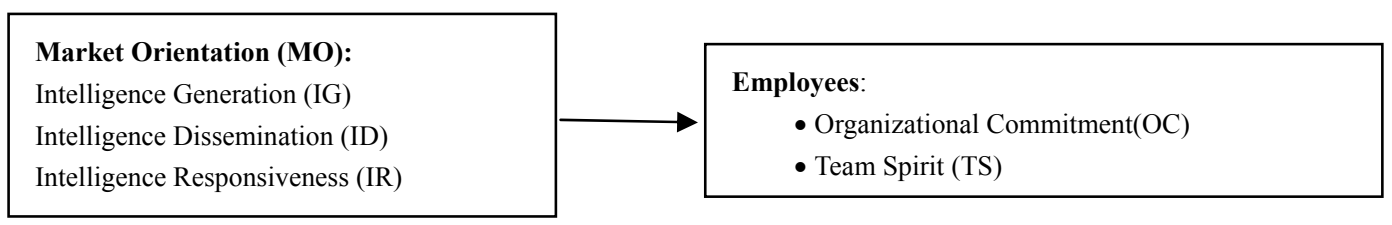

Figure 1. Market Orientation Model: Adapted from Kohli and Jaworski (1990)

According to Kohli and Jaworski (1990) market orientation provides psychological and social benefits to employees. They argue that market orientation leads to a sense of pride in belonging to an organization in which all departments and individuals are willing to work together towards the common objective of achieving organizational goals and that this positive response towards the work situation is a reflection of increased organizational commitment and team spirit. Based on this argument we expect that in the case of retail businesses in Botswana a higher level of market orientation will be associated with a higher level of organizational commitment. Similarly, we expect that high levels of market orientation will be associated with a high degree of team spirit.

Based on the conceptual model used in this study and the insights derived from the extant literature the following hypotheses relating to $\mathrm{MO}$ and its effects on organizational commitment and team spirit in the retail sector in Botswana are proposed:

H1: $M O$ is positively and significantly related to $O C$ (i.e. the higher the level of $M O$ the higher the organizational commitment of employees).

H2: $M O$ is positively and significantly related to TS (i.e. the higher the level of MO the higher the team spirit among employees).

\section{Methodology}

\subsection{Sample and Data Collection Procedures}

Data was collected in five major cities and towns in Botswana through personal interviews involving owners or managers of retail outlets in Botswana. The sampling frame included retail firms listed in the yellow pages of the telephone directory from which a random sample was selected. In order to facilitate cooperation an introductory letter explaining the purpose of the study and its benefits and requesting the organization to participate in the study was first presented to the officer in charge of the retail store such as manager, supervisor or CEO. Upon consent, the officer was then requested to identify a knowledgeable individual who can complete the questionnaire. The questionnaire was designed for self-administration under the overall supervision of the researchers who provided guidance or clarification as required. Consistent with previous studies the questionnaire was pretested in order to refine the measurement instrument.

A total of 274 firms responded with usable questionnaires. The bulk of the respondents came from the two main urban areas of Botswana (Gaborone and Francistown), which accounted for about 61 percent of the respondents surveyed. The largest single group of industry represented in the sample was clothing and textile with 39 percent of the firms, followed by supermarkets at 9 percent. The majority of the respondent personnel were managers, 
accounting for about 52 percent of the total. This suggests that most respondents were sufficiently experienced to be able to provide meaningful answers to broader policy issues relating to market orientation. This point is further reinforced by the fact that $69 \%$ per cent of the respondents were from the marketing / sales areas; people who are more likely than other departments to be conversant with marketing orientation issues.

\section{Analysis}

To examine the effect of MO on organizational commitment (OC) and team spirit (TS) a series of bivariate and multiple regression analysis were performed. Bivariate regression involves one dependent variable and one independent variable. In this study two bivariate regression analyses were carried out to examine the effect of MO (independent variable) on each one of the two dependent variables, namely, OC and TS. Multiple regression analysis involves one dependent variable and two or more independent variables. In this study the two dependent variables $\mathrm{OC}$ and TS were regressed individually with the three dimensions of MO (i.e. IG, ID and IR) to determine their relative impacts on the dependent variables. All the three predictor variables were entered simultaneously into the regression model.

\subsection{Measurement Scales}

All variables included in this study were measured on multiple-item scales adapted from previous studies. MO was measured using the scale adapted from Kohli, Jaworski and Kumar (1993). After adaptation, a scale consisting of 18 items was produced. OC and TS were measured by two 4-item scales. The OC scale items tap the extent which employees are proud to work for the company and are happy to make personal sacrifices for the company's well-being. The TS scale assessed the extent to which a team spirit prevails in the organization. For example, one item was used to measure the extent to which employees are "genuinely concerned about the needs and problems of each other". A five point scoring format ( $1=$ Strongly Disagree; $5=$ Strongly Agree) was employed for all items. All constructs assessed by more than one item were consolidated into a single variable.

\subsection{Scale Reliability}

Reliability of the scales used in this study was determined using Cronbach's alpha coefficient (Table 1). To ensure homogeneity and internal consistency all the items used were examined for correlation to total scores. By convention, items with item-to-total correlations of less than 0.3 should be deleted in order to improve overall alpha (Nannuly, 1967). Similarly one may wish to drop an item which if deleted alpha is higher than the overall alpha as a way to improve the overall alpha level. Only one item of the ID dimension was deleted for this reason. This lends further credibility to the reliability of the scale used. Alpha coefficients for the different constructs ranged from $0.537-0.749$. Nunnally $(1967$, p. 226$)$ suggest that the reliability of $0.50-0.60$ is sufficient although a coefficient of 0.7 and above is desirable (Hair et al. 1998). For this research the alpha coefficients for MO and IR exceed 0.7 while those for ID, OC, and TS exceed 0.60 . Therefore Alpha coefficients for the constructs used in this study show acceptable levels of internal consistency and homogeneity (Nunnally, 1967; Churchill, 1979).

\subsection{Multicollinearity}

Multicollinearity is the degree to which the independent variables are correlated with each other. The more the independent variables are correlated with each other the higher the multicollinearity. Multicollinearity can adversely affect the results of regression analysis and therefore the findings of the study. By convention, the Pearson's $r$ between each pair of the independent variables should not exceed 0.8 (Berry \& Feldman, 1985). As reflected in Table 1 the correlation coefficients of each pair of the independent falls below 0.8 which means that there is no problem of multicollinearity.

It is also worth noting that the mean score for MO is relatively low (Table 1) suggesting that retail businesses in Botswana are not highly market oriented (Marandu \& Themba, 2009). On the contrary, the mean scores for both OC (4.16) and TS (4.02) are quite high which implies that despite the relatively low level of market orientation, employees of retail businesses in Botswana are committed to their organizations and value working as a team.

Table 1. Dimensional statistics and Pearson correlation coefficients

\begin{tabular}{llllllllllll}
\hline Dimension & Mean & Std. deviation & Min. & Max. & Alpha & IG & ID & IR & MO & OC & TS \\
\hline ID & 3.83 & .735 & 1.33 & 5.00 & .659 & .451 & 1 & & & & \\
IR & 3.98 & .576 & 2.25 & 5.00 & .749 & .545 & .491 & 1 & & & \\
MO & 3.90 & .482 & 2.29 & 5.00 & .747 & .763 & .847 & .821 & 1 & & \\
OC & 4.16 & .485 & 3.00 & 5.00 & .650 & .374 & .302 & .281 & .383 & 1 & \\
TS & 4.02 & .505 & 2.75 & 5.00 & .604 & .325 & .205 & .264 & .312 & .573 & 1 \\
\hline
\end{tabular}




\section{Results}

The results of regression analysis (Table 2) show that market orientation has a significant positive effect on organizational commitment $\left(\mathrm{R}^{2}=0.147\right)$. Based on this result $\mathrm{H} 1$ is confirmed. The regression results also indicate that market orientation influence team spirit in the expected direction $\left(\mathrm{R}^{2}=0.094\right)$. However, the relationship is not sufficiently robust. On the basis of this result $\mathrm{H} 2$ is not supported. Further analysis was conducted to determine the relative influence of each of the dimensions of market orientation on organizational commitment and team spirit. Only IG dimension of market orientation has a significant effect on both commitment (beta $=0.286 ; \mathrm{p}<.001$ level) and team spirit $($ beta $=0.248 ; \mathrm{p}<.01)$.

Table 2. Results of bivariate and multiple regression analysis

\begin{tabular}{lllll}
\hline & Model 1 & Model 2 & Model 3 & Model 4 \\
& Y= OC & Y=TS & Y= OC & Y=TS \\
& $\mathrm{X}_{1}=$ MO & $\mathrm{X}_{1}=\mathrm{MO}$ & $\mathrm{X}_{1}=\mathrm{IG}$ & $\mathrm{X}_{1}=\mathrm{IG}$ \\
& & $\mathrm{X}_{2}=\mathrm{ID}$ & $\mathrm{X}_{2}=\mathrm{ID}$ \\
& & & $\mathrm{X}_{3}=\mathrm{IR}$ & $\mathrm{X}_{3}=\mathrm{IR}$ \\
\hline $\mathrm{R}^{2}$ & .147 & .097 & .193 & .119 \\
$\mathrm{Adj} . \mathrm{R}^{2}$ & .144 & .094 & .181 & .106 \\
$\mathrm{~F}$ & $47.096^{* * *}$ & 29.494 & 16.077 & 9.100 \\
$\mathrm{t}$ & 6.863 & 5.431 & - & - \\
Beta & $.785^{* * *}$ & $\mathrm{~ns}$ & $\mathrm{IG}=0.286^{* * *}$ & $\mathrm{IG}=0.248^{* *}$ \\
\hline
\end{tabular}

Note: ns=not significant; ${ }^{*} \mathrm{p}<.05 ;{ }^{* *} \mathrm{p}<.01 ; * * \mathrm{p}<.001$. Dependent variables: OC; TS. Independent variables: MO ; IG ; ID; IR.

\section{Discussions}

Previous studies have indicated that market orientation increases organizational commitment and that it also engenders a spirit of team work among employees (e.g. Ruekert, 1992; Jaworski \& Kohli, 1993; Selnes et al., 1996). The present study applies the MARKOR scale to investigate the posited influence of market orientation on employees in a specific context of retail business sector in Botswana. The results of the present study provide further empirical support for the posited link between market orientation and organizational commitment. The results also provide further credence to the notion that the marketing concept is a worthwhile business philosophy to implement even in a developing nation context.

Contrary to the findings of previous studies the present study does not lend support to the posited effect of market orientation on team spirit. Although this finding seems to be counter intuitive, it does not necessarily follow that if market orientation fosters organizational commitment it should also engender a spirit of team work among employees. Organizational commitment and team spirit are different aspects of employee behavior which can be affected by different factors. For example, although organizational commitment is critical for both small and large organizations, team work is less critical in small organizations. Previous studies which have provided evidence for the posited link between MO and team spirit (e.g. Ruekert, 1992; Jaworski \& Kohli, 1993; Selnes et al., 1996) have been conducted mostly in large organizations. This suggests that MO only has a significant effect on team spirit in large organizations and that organizational size has a moderating effect on market orientation and its effects on team spirit. The fact that the majority of retail businesses in Botswana are relatively small in size (Iyanda et al., 2009) may explain the results of the present study.

In addition to the main findings discussed above, the present study indicates that retail businesses in Botswana are not actively involved in market orientation activities such as organization-wide market intelligence gathering, organization-wide dissemination of such intelligence and organization-wide responsiveness to it. Nevertheless, the study finds that employees in retail businesses display some degree of organizational commitment. Furthermore the study provides further proof that the MARKOR scale is applicable in the retail sector.

\section{Managerial Implications}

From a managerial perspective the results of the present study suggest that there is much more to be gained from adopting and implementing market orientation in addition to performance improvement as many previous studies have found out (e.g. Jaworski \& Kohli, 1993; Narver \& Slater, 1990). The results of the present study indicate that market orientation makes employees fond of the organization they work for and willing to make personal sacrifices in order to achieve organizational goals. According to Caruana and Calleya (1998) such a commitment to the organization can lead to improved service quality, productivity and profitability. However, the results of the present study also suggests that in the case of retail businesses in Botswana engaging in activities related to market 
orientation would not lead to significant improvement in team spirit among employees.

\section{Limitations and Directions for Future Research}

The present study has a few major limitations which serve as basis for future research. First, although the study investigated MO and its effects on employees in diverse retail businesses, it did not take into consideration the potential moderating effects of the contextual variables on organizational commitment and term spirit. Jaworski and Kohli (1993) have noted the need to consider the moderating effects of the contextual variables such as market turbulence, competitive intensity and technological turbulence on MO outcomes. The different product categories involved in the present study have the potential to moderate the effects of $\mathrm{MO}$ on employees. To address this problem there is need for future studies to either focus on single product categories, say, furniture or food products or conduct comparative studies of various product categories.

Second, although the study investigated the effects of market orientation on employees, data was collected from supervisors, managers, heads of departments and owners rather than from employees themselves. Most of the previous researchers in this area have also used the same approach. However, this raises the question whether these high ranking officials accurately reflect the views, opinions and experiences of the rank and file employees (Harris \& Ogbonna, 2000). Future research should therefore collect data directly from employees themselves to determine the effects of $\mathrm{MO}$ on employees.

Finally, previous studies have shown that MO has an effect on other behavioral job outcomes such as job satisfaction and employee turnover. However the present study focused only on organizational commitment and team spirit. For a more comprehensive understanding of the effects of market orientation on employees in the retail setting, future studies should be more broadly encompassing in terms of the behavioral outcomes investigated.

\section{References}

A T Kearney, Report. (2012). The 2012 A.T. Kearney Global Retail Development Index.

Berry, W., \& Feldman, S. (1985). Multiple Regression in Practice. Beverly Hill CA: Sage Publications.

Caruana, A. (1997). Market orientation and organizational commitment in the Australian public sector. International Journal of Public Sector Management, 10(4), 294-303. http://dx.doi.org/10.1108/09513559710180556

Caruana, A., \& Calleya, P. (1998). The effect of internal marketing on organizational commitment among retail bank managers. International Journal of Bank Marketing, 16(3), 108-116. http://dx.doi.org/10.1108/02652329810213510

Castro, C. B., Armario, E. M., \& Sanchez del Rio, M. E. (2005). Consequences of market orientation for customers and employees. European Journal of Marketing, 39(5/6), 646-675. http://dx.doi.org/10.1108/03090560510590755

Chelariu, C., Ouattarra, A., \& Dadzie, K. Q. (2002). Market orientation in Ivory Coast: measurement validity and organizational antecedents in a sub-Saharan African economy. The Journal of Business \& Industrial Marketing, 17(6), 456-470. http://dx.doi.org/10.1108/08858620210442811

Churchill, G. A. (1979). A paradigm for developing better measures of marketing constructs. Journal of Marketing Research, 16(February), 64-73. http://dx.doi.org/10.2307/3150876

Diamantopoulos, A., \& Hart, S. (1993). Linking market orientation and company performance evidence on Kohli $\begin{array}{llll}\text { and Jaworski's framework. Journal of Strategic Marketing, } 1, & 93-121 .\end{array}$ http://dx.doi.org/10.1080/09652549300000007

Drucker, P. F. (1954). The Practice of Management. New York: Harper and Row Publishers.

Ellis, P. D. (2005). Market orientation and marketing practice in a developing economy. European Journal of Marketing, 39(5/6), 629-645. http://dx.doi.org/10.1108/03090560510590746

Hair, Jr. J. F., Wolfinbarger, M. F., Ortnau, D. J., \& Bush, R. P. (2010). Essentials of Marketing Research. New York: McGraw-Hill Irwin.

Harris, L. C., \& Ogbonna, E. (2000). The responses of front-line employees to market-oriented culture change. European Journal of Marketing, 34(3/4), 318-340. http://dx.doi.org/10.1108/03090560010311885

Iyanda, O., Makgosa, R., Phambuka-Nsimbi, C., \& Themba, G. (2009). Retailing and Sustainable Development in Botswana. Report Prepared for Trust Africa and ICBE. http://www.trustafrica.org/documents/research_funding/Iyanda.pdf: Accessed: 15/6/2012 
Jaworski, B. J., \& Kohli, A. K. (1993). Market orientation: Antecedents and Consequences. Journal of Marketing, 57, 53-70. http://dx.doi.org/10.2307/1251854

Kohli, A. K., \& Jaworski, B. J. (1990). Market Orientation: The construct, research propositions and managerial implications. Journal of Marketing, 54(April), 1-18. http://dx.doi.org/10.2307/1251866

Kohli, A. K., Jaworski, B. J., \& Kumar, A. (1993). MARKOR: a measure of market orientation. Journal of Marketing Research, 30(4), 467-478. http://dx.doi.org/10.2307/3172691

Kuada, J., \& Buatsi, S. (2005). Market orientation and management practices in Ghanaian firms: Revising Jaworski and Kohli. Journal of International Marketing, 13(1), 58-88. http://dx.doi.org/10.1509/jimk.13.1.58.58539

Mahmoud, M. A. (2011). Market Orientation and Business Performance among SMEs in Ghana. International Business Research, 4(1), 241-251.

Marandu, E., \& Themba, G. (2009). Market Orientation-Business Performance Link: Empirical Evidence from Botswana. African Journal of Marketing, 4, 4-52.

Narver, J. C., \& Slater, S. F. (1990). The effect of market orientation on business profitability. Journal of Marketing, 54(October), 20-35. http://dx.doi.org/10.2307/1251757

Nunnaly, J. (1967). Psychometric theory. New York: McGraw-Hill.

Nunnaly, J. (1978). Psychometric theory. New York: McGraw-Hill.

Pitt, L., Caruana, A., \& Berthon, P. (1996). Market orientation and business performance: some European evidence. International Marketing Review, 13(1), 5-18. http://dx.doi.org/10.1108/02651339610111317

Powpaka, S. (2006). How market orientation affects female service employees in Thailand. Journal of Business Research, 59, 54-61. http://dx.doi.org/10.1016/j.jbusres.2005.03.004

Rod, M., \& Ashill, N. J. (2010). The effect of customer orientation on frontline employees job outcomes in a new public management context. Marketing Intelligence \& Planning, 28(5), 600-624. http://dx.doi.org/10.1108/02634501011066528

Ruekert, R. W. (1992). 'Developing a Market Orientation: An Organizational Strategy Perspective. International Journal of Research in Marketing, 9(3), 225-245. http://dx.doi.org/10.1016/0167-8116(92)90019-H

Selness, F., Jaworski, B. J., \& Kohli, A. J. (1996). Market Orientation in United States and Scandinavian Companies. A Cross-Cultural Study. Scandinavian Journal of Management, 12(2), 139-157. http://dx.doi.org/10.1016/0956-5221(95)00053-4

Shoham, A., Rose, G. M., \& Kropp, F. (2005). Market orientation and performance: a meta-analysis. Marketing Intelligence \& Planning, 23(5), 435-451. http://dx.doi.org/10.1108/02634500510612627

Siguaw, J. A., Brown, G., \& Widing, II, R. E. (1994). The influence of the Market Orientation of the Firm on Sales Force Behavior and Attitudes. Journal of Marketing Research, XXXI(February), 106-116. http://dx.doi.org/10.2307/3151950

Winston, E., \& Dadzie, K. Q. (2002). Market orientation of Nigerian and Kenyan firms: the role of top managers. Journal of Business and Industrial Marketing, 17(6), 471-480. http://dx.doi.org/10.1108/08858620210442820 